\title{
SURVIVORSHIP OF CEMENTED KNEE REPLACEMENTS
}

\author{
GILES R. SCUDERI， JOHN N. INSALL， RUSSELL E. WINDSOR, MICHAEL C. MORAN
}

From The Hospital for Special Surgery and Cornell University Medical College, New York

The survivorship method of analysis has been used to compare the failure rate and overall success of 1430 cemented primary total knee arthroplasties performed at The Hospital for Special Surgery over a 15year period. There were 224 total condylar prostheses with a polyethylene tibia, 289 of the posterior stabilised type with an all polyethylene tibia, and 917 posterior stabilised with a metal-backed tibial component.

There were 12 failures in the total condylar series, giving an average annual failure rate of $0.65 \%$ and a 15-year success rate of $\mathbf{9 0 . 5 6 \%}$. The posterior stabilised prosthesis with a polyethylene tibia showed an average annual failure rate of $0.27 \%$ and a 10 -year success rate of $97.34 \%$, and this prosthesis with a metalbacked tibial component gave an annual failure rate of $0.19 \%$ and a seven-year success rate of $98.75 \%$.

The overall survival rate was not influenced by sex or age, diagnosis or the percentage of ideal body weight. No metal-backed tibial components have yet needed revision for loosening. It seems that infection will be the major cause of failure.

Total knee replacement has evolved to afford the orthopaedic surgeon the ability to correct deformity, maintain movement and relieve pain. Most current designs of implant are successful but many reports contain information based on limited follow-up periods (Insall, Scott and Ranawat 1979; Insall, Lachiewicz and Burstein 1982; Insall et al 1983; Insall and Kelly 1986; Vince, Kelly and Insall 1988). The variation in follow-up makes it difficult to interpret and compare results since failure rates are time-dependent. The ultimate concern is how long can total knee replacement be expected to last.

Survivorship analysis has been advocated as providing annual and overall failure rates, as well as the probabilities of implant survival (Dobbs 1980; Tew and Waugh 1982; Grimer, Karpinski and Edwards 1984; Lettin et al 1984; Lewallen, Bryan and Peterson 1984; Knutson, Tjörnstrand and Lidgren 1985; Tew, Waugh and Forster 1985; Knutson, Lindstrand and Lidgren 1986; Ritter and Campbell 1987; Vince et al 1988). Survivorship analysis is easy to apply since the end-point can be clear cut and will provide a conservative estimate

G. R. Scuderi, MD, Fellow in Orthopaedics

J. N. Insall, MD, Attending Orthopaedic Surgeon

R. E. Windsor, MD, Assistant Attending Orthopaedic Surgeon

M. C. Moran, MD, Resident in Orthopaedics

The Knee Service, The Hospital for Special Surgery, 535 East 70th

Street, New York, New York 10021, USA

Correspondence should be sent to Dr J. N. Insall.

(C) 1989 British Editorial Society of Bone and Joint Surgery

$0301-620 X / 89 / 5197 \$ 2.00$

J Bone Joint Surg [ Br] 1989; 71-B:798-803. of failure over time. It also allows the inclusion of some data from patients with short follow-up, those lost to follow-up and those who have died. When the same definition of failure is used comparison between different prostheses is possible.

The total condylar prosthesis was first used in January 1974 and is still successful (Insall et al 1979; Insall et al 1983; Insall and Kelly 1986). Evolution led to the posterior stabilised modification in 1978; this was designed to improve the range of movement, making stair climbing easier, and to prevent posterior tibial subluxation (Insall et al 1982). At first, the posterior stabilised tibial component was made entirely of polyethylene, but it was later shown that metal-backed tibial trays transmit load better (Bartel et al 1982). In November 1980 we began to use metal-backed tibial components and in October 1981 made the last use of the allpolyethylene type.

We have now applied the survivorship method of analysis to our series of cemented primary knee replacements with these prostheses.

\section{MATERIALS AND METHODS}

From 1974 to 1986,1430 cemented primary total knee arthroplasties were performed by or under the direct supervision of the senior author (JNI) at The Hospital for Special Surgery and are available for analysis. The review includes 224 total condylar prostheses with a polyethylene tibial component (1974 to 1978), 289 posterior stabilised type with an all polyethylene tibial 
component (1978 to 1981), and 917 posterior stabilised with a metal-backed tibial component (1981 to 1986). There were 445 knees in men and 985 in women, with an average age of 67 years (range 20 to 87 ) and an average body weight $135 \%$ of the ideal (range $70.4 \%$ to $308.6 \%$ ). There were 1117 osteoarthritic knees, 193 rheumatoid knees, and 120 knees with other diagnoses including osteonecrosis, post-traumatic arthritis, psoriatic arthritis and haemophilia.

Survivorship analysis used the method described by Armitage (1971); life tables were constructed with each knee replacement entered only once and having one of three possible outcomes for a particular interval: success, failure, or withdrawal. Success was defined as a prosthesis still in situ at the end of the follow-up regardless of clinical score. Failure was defined as a prosthesis revised for any cause or one for which revision has been recommended but not yet performed. Patients who died or were lost to follow-up were withdrawn from the life table as from the date of their last evaluation. The implicit assumption is that lost and dead patients would otherwise be subject to the same probability of failure as the balance of the cohort. The length of follow-up for each patient was determined from routine clinic and office notes, but when a patient had not been seen for a prolonged period, the date of response to a mailed questionnaire was accepted. The latest reviews were in April 1988.

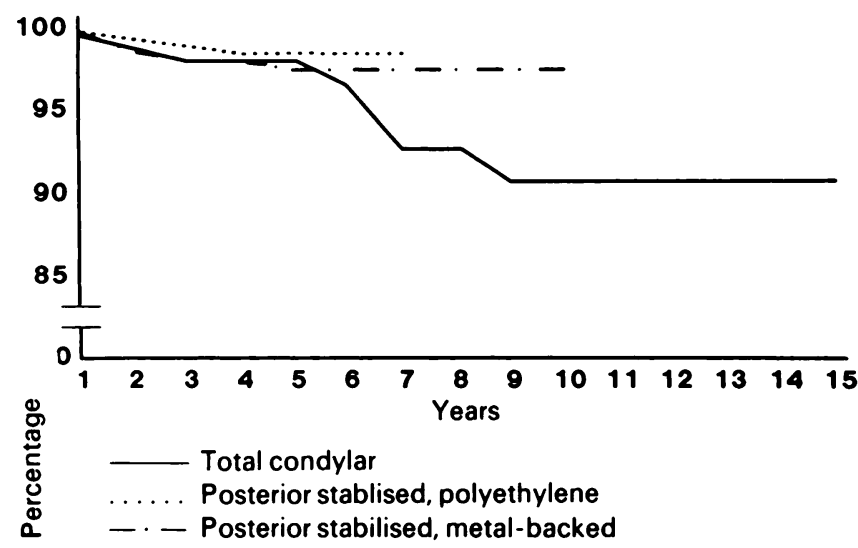

Fig. 1

Survival curves for three patterns of total knee prosthesis.

Survivorship tables were constructed using 12month intervals and recording, for each interval after surgery, the total number of knee replacements entering the interval, the numbers of failures and withdrawals, the number at risk, the annual failure and success rates, and the cumulative success rate (Table I).

Variables such as pathological diagnosis, sex, age and weight were subjected to survivorship analysis to determine their significance for the longevity of total knee replacement. Those with diagnoses of osteoarthritis, rheumatoid arthritis, post-traumatic arthritis, osteonecrosis and other diseases were assessed separately. Age at the time of surgery, was recorded as 55 years or younger or as over 55 years. The ideal body weight was calculated for each patient, and separate life tables were constructed for those patients at $110 \%$ or less of their ideal and those over $110 \%$. The significance of the difference between the survival rates for each prosthesis was determined.

\section{RESULTS}

The data for the different prostheses are given in Tables I to IV and the survival curves which result are shown in Figure 1. There were 12 failures in the total condylar series with an average annual failure rate of $0.65 \%$ and a 15 -year overall success rate of $90.56 \%$. The posterior stabilised prosthesis with a polyethylene tibia gave six failures with an average annual failure rate of $0.27 \%$ and a 10 -year overall success rate of $97.34 \%$. The posterior stabilised prosthesis with a metal-backed tibia gave seven failures with an average annual failure rate of $0.19 \%$ and a seven year overall success rate of $98.75 \%$.

Failure in the total condylar series included three cases of infection, four loose tibial components, two loose femoral and tibial components, two unstable arthroplasties and one femoral supracondylar fracture. There were no reported revisions later than nine years. For the posterior stabilised prosthesis with a polyethylene tibia, failures included two loose tibial components, three loose femoral components and one tibial stress fracture. The failures in the metal-backed posterior stabilised group were six infections and one loose femoral component. There were no revisions after five years with the posterior stabilised type with a polyethylene tibia or after four years with the metal-backed prosthesis. No metal-backed tibial components have yet been revised for loosening. The incidence of femoral loosening requiring revision was $0.89 \%$ in the total condylar group and $0.33 \%$ in the combined posterior stabilised group. The overall incidence of infection for all total knee replacements was $0.63 \%$.

The survivorship curves were not significantly affected by diagnosis, sex, age or body weight (Tables IA, IIA, IIIA and IV).

\section{DISCUSSION}

The survivorship method of analysis makes it possible to compare the failure rate and the overall success rate of different knee replacements. Tew and Waugh (1982) suggested that survivorship analysis may be more accurate than the conventional method of measuring failure. Since the patient population in joint replacement is older, patients may have died, been incapacitated by serious illnesses or lost to follow-up. Survivorship analysis 
Table I. Life table for the original total condylar prosthesis (TCPI)

\begin{tabular}{|c|c|c|c|c|c|c|c|}
\hline \multirow[b]{2}{*}{$\begin{array}{l}\text { Follow-up } \\
\text { interval* }\end{array}$} & \multicolumn{4}{|l|}{ Number } & \multicolumn{3}{|l|}{ Annual } \\
\hline & $\begin{array}{l}\text { Entering } \\
\text { interval } \\
\text { (1) }\end{array}$ & $\begin{array}{l}\text { Failures } \\
\text { (2) }\end{array}$ & $\begin{array}{l}\text { Withdrawals } \\
\text { (3) }\end{array}$ & $\begin{array}{l}\text { At risk } \\
\text { (4) }\end{array}$ & $\begin{array}{l}\text { Failure } \\
\text { (5) }\end{array}$ & $\begin{array}{l}\text { Success } \dagger \\
\text { (6) }\end{array}$ & $\begin{array}{l}\text { Overall } \\
\text { success } \\
\text { (7) }\end{array}$ \\
\hline 0 to 12 & 224 & 1 & 28 & 210 & 0.48 & 99.52 & 99.52 \\
\hline 13 to 24 & 195 & 2 & 16 & 187 & 1.07 & 98.93 & 98.46 \\
\hline 25 to 36 & 177 & 1 & 19 & 167.5 & 0.60 & 99.40 & 97.86 \\
\hline 37 to 48 & 157 & 0 & 7 & 153.5 & 0 & 100 & 97.86 \\
\hline 49 to 60 & 150 & 0 & 18 & 141 & 0 & 100 & 97.86 \\
\hline 61 to 72 & 132 & 2 & 23 & 120.5 & 1.66 & 98.34 & 96.24 \\
\hline 73 to 84 & 107 & 4 & 3 & 105.5 & 3.79 & 96.21 & 92.59 \\
\hline 85 to 96 & 100 & 0 & 6 & 97 & 0 & 100 & 92.59 \\
\hline 97 to 108 & 94 & 2 & 5 & 91.5 & 2.18 & 97.81 & 90.56 \\
\hline 109 to 120 & 87 & 0 & 16 & 79 & 0 & 100 & 90.56 \\
\hline 121 to 132 & 71 & 0 & 20 & 61 & 0 & 100 & 90.56 \\
\hline 133 to 144 & 51 & 0 & 13 & 44.5 & 0 & 100 & 90.56 \\
\hline 145 to 156 & 38 & 0 & 28 & 24 & 0 & 100 & 90.56 \\
\hline 157 to 168 & 10 & 0 & 9 & 5.5 & 0 & 100 & 90.56 \\
\hline 169 to 180 & 1 & 0 & 1 & 0.5 & 0 & 100 & 90.56 \\
\hline
\end{tabular}

The number of surviving knee replacements at the start of each interval (Column 1) is obtained by subtracting the number of failures (Column 2) and number of withdrawals (Column 3 ) within the previous interval from the number of survivors at the start of the previous interval. For any given interval the number of implants at risk (Column 4) is obtained by subtracting half the number of withdrawals from the start of the interval. It is assumed for convenience that the withdrawals survived half the interval. The percentage of failures (Column 5) within any interval is obtained by dividing the number of failures by the number at risk and multiplying by 100 . The percentage of successes (Column 6 ) is obtained by subtracting the probability of failure from 100 . The overall success rate (Column 7) is obtained by the successive multiplication of the probability of success. From the life tables, survival curves are derived.

Table IA. Overall success rates for TCPI broken down for diagnosis, sex, age and body weight

\begin{tabular}{|c|c|c|c|c|c|c|c|c|}
\hline \multirow{2}{*}{$\begin{array}{l}\text { Follow-up } \\
\text { interval* }\end{array}$} & \multicolumn{2}{|c|}{ Diagnosis } & \multicolumn{2}{|l|}{ Sex } & \multicolumn{2}{|l|}{ Age } & \multicolumn{2}{|c|}{ Ideal body weight } \\
\hline & $\mathbf{O A}$ & $\mathbf{R A}$ & Male & Female & $<55$ years & $>55$ years & $<110 \%$ & $>110 \%$ \\
\hline 0 to 12 & 99.36 & 100 & 97.75 & 100 & 100 & 99.49 & 97.40 & 100 \\
\hline 13 to 24 & 98.65 & 100 & 97.75 & 98.67 & 95.35 & 98.89 & 97.40 & 98.72 \\
\hline 25 to 36 & 97.86 & 100 & 94.95 & 98.67 & 95.35 & 98.22 & 97.40 & 98.02 \\
\hline 37 to 48 & 97.86 & 100 & 94.95 & 98.67 & 95.35 & 98.22 & 97.40 & 98.02 \\
\hline 49 to 60 & 97.86 & 100 & 94.95 & 98.67 & 95.35 & 98.22 & 97.40 & 98.02 \\
\hline 61 to 72 & 95.43 & 100 & 94.95 & 96.60 & 85.31 & 98.22 & 91.50 & 97.08 \\
\hline 73 to 84 & 95.43 & 94.74 & 94.95 & 92.03 & 79.98 & 94.93 & 84.18 & 93.91 \\
\hline 85 to 96 & 94.07 & 94.74 & 94.95 & 92.03 & 79.98 & 94.93 & 84.18 & 93.91 \\
\hline 97 to 108 & 94.07 & 89.17 & 90.21 & 90.74 & 79.98 & 92.50 & 84.18 & 91.61 \\
\hline 109 to 120 & 94.07 & 89.17 & 90.21 & 90.74 & 79.98 & 92.50 & 84.18 & 91.61 \\
\hline 121 to 132 & 94.07 & 89.17 & 90.21 & 90.74 & 79.98 & 92.50 & 84.18 & 91.61 \\
\hline 133 to 144 & 94.07 & 89.17 & 90.21 & 90.74 & 79.98 & 92.50 & 84.18 & 91.61 \\
\hline 145 to 156 & 94.07 & 89.17 & 90.21 & 90.74 & 79.98 & 92.50 & 84.18 & 91.61 \\
\hline 157 to 168 & 94.07 & 89.17 & 90.21 & 90.74 & 79.98 & 92.50 & 84.18 & 91.61 \\
\hline
\end{tabular}

* months + per cent 
Table II. Life table for posterior stabilised TCP with an all-polyethylene tibial component

\begin{tabular}{|c|c|c|c|c|c|c|c|}
\hline \multirow[b]{2}{*}{$\begin{array}{l}\text { Follow-up } \\
\text { interval }\end{array}$} & \multicolumn{4}{|l|}{ Number } & \multicolumn{3}{|l|}{ Annual } \\
\hline & $\begin{array}{l}\text { Entering } \\
\text { interval }\end{array}$ & Failures & Withdrawals & At risk & Failure† & Successt & $\begin{array}{c}\text { Overall } \\
\text { success } \dagger\end{array}$ \\
\hline 0 to 12 & 289 & 1 & 41 & 268.5 & 0.37 & 99.63 & 99.63 \\
\hline 13 to 24 & 247 & 3 & 18 & 238 & 1.26 & 98.74 & 98.37 \\
\hline 25 to 36 & 226 & 1 & 25 & 213.5 & 0.47 & 99.53 & 97.91 \\
\hline 37 to 48 & 200 & 0 & 19 & 192 & 0 & 100 & 97.91 \\
\hline 49 to 60 & 181 & 1 & 15 & 173.5 & 0.58 & 99.42 & 97.34 \\
\hline 61 to 72 & 165 & 0 & 45 & 142.5 & 0 & 100 & 97.34 \\
\hline 73 to 84 & 120 & 0 & 26 & 107 & 0 & 100 & 97.34 \\
\hline 85 to 96 & 94 & 0 & 39 & 74.5 & 0 & 100 & 97.34 \\
\hline 97 to 108 & 55 & 0 & 48 & 31 & 0 & 100 & 97.34 \\
\hline 109 to 120 & 7 & 0 & 7 & 3.5 & 0 & 100 & 97.34 \\
\hline
\end{tabular}

* months † per cent

Table IIA. Overall success rates for posterior stabilised TCP with an all-polyethylene tibial component broken down for diagnosis, sex, age and body weight

\begin{tabular}{|c|c|c|c|c|c|c|c|c|}
\hline \multirow{2}{*}{$\begin{array}{l}\text { Follow-up } \\
\text { interval** }\end{array}$} & \multicolumn{2}{|c|}{ Diagnosis } & \multicolumn{2}{|l|}{ Sex } & \multicolumn{2}{|l|}{ Age } & \multicolumn{2}{|c|}{ Ideal body weight } \\
\hline & $\mathbf{O A}$ & $\mathbf{R A}$ & Male & Female & $<55$ years & $>55$ years & $<110 \%$ & $>110 \%$ \\
\hline 0 to 12 & 100 & 97.37 & 100 & 99.50 & 97.37 & 100 & 97.78 & 100 \\
\hline 13 to 24 & 98.36 & 97.37 & 98.40 & 98.37 & 97.37 & 98.53 & 97.78 & 98.48 \\
\hline 25 to 36 & 97.76 & 97.37 & 98.40 & 97.75 & 97.37 & 97.98 & 97.78 & 97.95 \\
\hline 37 to 48 & 97.76 & 97.37 & 98.40 & 97.75 & 97.37 & 97.98 & 97.78 & 97.95 \\
\hline 49 to 60 & 97.07 & 97.37 & 96.08 & 97.75 & 97.37 & 97.31 & 94.90 & 97.95 \\
\hline 61 to 72 & 97.07 & 97.37 & 96.08 & 97.75 & 97.37 & 97.31 & 94.90 & 97.95 \\
\hline 73 to 84 & 97.07 & 97.37 & 96.08 & 97.75 & 97.37 & 97.31 & 94.90 & 97.95 \\
\hline 85 to 96 & 97.07 & 97.37 & 96.08 & 97.75 & 97.37 & 97.31 & 94.90 & 97.95 \\
\hline 97 to 108 & 97.07 & 97.37 & 96.08 & 97.75 & 97.37 & 97.31 & 94.90 & 97.95 \\
\hline 109 to 120 & 97.07 & 97.37 & 96.08 & 97.75 & 97.37 & 97.31 & 94.90 & 97.95 \\
\hline
\end{tabular}

* months

Table III. Life table for posterior stabilised TCP with a metal-backed tibial component

\begin{tabular}{|c|c|c|c|c|c|c|c|}
\hline \multirow[b]{2}{*}{$\begin{array}{l}\text { Follow-up } \\
\text { interval* }\end{array}$} & \multicolumn{4}{|l|}{ Number } & \multicolumn{3}{|l|}{ Annual } \\
\hline & $\begin{array}{l}\text { Entering } \\
\text { interval } \\
\text { (1) }\end{array}$ & $\begin{array}{l}\text { Failures } \\
\text { (2) }\end{array}$ & $\begin{array}{l}\text { Withdrawals } \\
\text { (3) }\end{array}$ & $\begin{array}{l}\text { At risk } \\
\text { (4) }\end{array}$ & $\begin{array}{l}\text { Failure† } \\
\text { (5) }\end{array}$ & $\begin{array}{l}\text { Successt } \\
\text { (6) }\end{array}$ & $\begin{array}{l}\text { Overall } \\
\text { success } \dagger \\
\text { (7) }\end{array}$ \\
\hline 0 to 12 & 917 & 3 & 89 & 872.5 & 0.34 & 99.66 & 99.66 \\
\hline 13 to 24 & 825 & 2 & 322 & 664 & 0.30 & 99.70 & 99.36 \\
\hline 25 to 36 & 501 & 1 & 169 & 416.5 & 0.24 & 99.76 & 99.12 \\
\hline 37 to 48 & 331 & 1 & 127 & 267.5 & 0.37 & 99.63 & 98.75 \\
\hline 49 to 60 & 203 & 0 & 92 & 157 & 0 & 100 & 98.75 \\
\hline 61 to 72 & 111 & 0 & 84 & 69 & 0 & 100 & 98.75 \\
\hline 73 to 84 & 27 & 0 & 27 & 13.5 & 0 & 100 & 98.75 \\
\hline
\end{tabular}

* months + per cent 
Table IIIA. Overall success rates for posterior stabilised TCP with a metal-backed tibial component broken down for diagnosis, sex, age and body weight

\begin{tabular}{|c|c|c|c|c|c|c|c|c|}
\hline \multirow{2}{*}{$\begin{array}{l}\text { Follow-up } \\
\text { interval* }\end{array}$} & \multicolumn{2}{|c|}{ Diagnosis } & \multicolumn{2}{|l|}{ Sex } & \multicolumn{2}{|l|}{ Age } & \multicolumn{2}{|c|}{ Ideal body weight } \\
\hline & $\mathbf{O A}$ & $\mathbf{R A}$ & Male & Female & $<55$ years & $>55$ years & $<110 \%$ & $>110 \%$ \\
\hline 0 to 12 & 99.55 & 100 & 99.32 & 99.81 & 100 & 99.61 & 100 & 99.73 \\
\hline 13 to 24 & 99.13 & 100 & 98.85 & 99.55 & 100 & 99.24 & 100 & 99.16 \\
\hline 25 to 36 & 98.80 & 100 & 98.85 & 99.14 & 100 & 98.95 & 100 & 98.86 \\
\hline 37 to 48 & 98.29 & 100 & 97.69 & 99.14 & 100 & 98.51 & 100 & 98.41 \\
\hline 49 to 60 & 98.29 & 100 & 97.69 & 99.14 & 100 & 98.51 & 100 & 98.41 \\
\hline 61 to 72 & 98.29 & 100 & 97.69 & 99.14 & 100 & 98.51 & 100 & 98.41 \\
\hline 73 to 84 & 98.29 & 100 & 97.69 & 99.14 & 100 & 98.51 & 100 & 98.41 \\
\hline
\end{tabular}

* months

allows some of the data from these patients to be included in long-term studies. It is assumed that patients who die or are lost to follow-up are subject to the same failure rate as the balance of the cohort. Although this assumption may not always be correct, any bias should affect all reporting equally in comparative series of knee arthroplasties. However, we believe that survivorship analysis becomes more valid when accompanied by a detailed analysis of a subset of the whole series. Hence we also present in this issue a paper reporting a 10 to 12 year study of the total condylar prosthesis (Vince, Insall and Kelly 1989 see pages 793 to 797 ).

For survivorship analysis the end-point and definition of failure must be clearly defined and reproducible. No standard clinical or radiographic grading system has been universally accepted; but the use of more sensitive end-points will obviously result in a higher failure rate. The quality of each result could not be considered in the survivorship analysis because of this difficulty of defining a precise and standard end-point. Pain is a nonspecific criterion because it is not objective, has a physician and patient bias and may not be related to the implant. Using revision or recommended revision provides an easily reproducible end-point and enables comparison with other prosthetic designs studied in a similar manner.

Our overall success rates indicate that changes in prosthetic design have improved the longevity of knee replacement, with seven year success in $92.6 \%$ of the total condylar prostheses, $97.3 \%$ of the posterior stabilised type with a polyethylene tibia and $98.8 \%$ for the posterior stabilised type with a metal-backed tibia. Since we have been using the metal-backed tibial component not one tibial component has been revised for loosening. The femoral loosening rate is also lower with the posterior stabilised component $(0.3 \%)$ when compared to the total condylar $(0.9 \%)$. This improvement may be partly due to better surgical technique in the posterior stabilised group. Infection has been the major cause of failure $(0.65 \%)$ in the posterior stabilised prosthesis with the metal-backed tibia.
Comparing our survivorship data with those from recent studies using the same definition of failure revealed similar results. Knutson et al (1985) reported a five-year overall survival rate of $100 \%$ for tricompartmental prostheses (total condylar, kinematic and porous coated anatomic) and in a nationwide multicentre study of 8000 knees Knutson et al (1986), report a six-year overall survival rate of $90 \%$ for similar prostheses.

Table IV. Overall success rates for the three types of prosthesis

\begin{tabular}{llll}
\hline & 7 years & 10 years & 15 years \\
\hline Original TCP & 92.59 & 90.56 & 90.56 \\
Posterior stabilised & & & \\
$\quad$ Polythene tibial & 97.34 & 97.34 & - \\
Metal-backed tibial & 98.75 & - & - \\
\hline
\end{tabular}

Our results do appear to be better than those for some earlier designs. Though some of these prostheses are now outdated, the results do provide long-term experience against which newer designs can be judged. Tew et al (1985) reported a six year survival of $72 \%$ in 365 replacements using the Freeman, Sheehan and Manchester prostheses and Lewallen et al (1984) reported a 10 year survival of $66 \%$ with the polycentric total knee. The longevity of our three prostheses is much better than that of the hinged arthroplasties. Grimer et al (1984) reported a seven year survival of $80 \%$ and Lettin et al (1984) an eight year survival of $83 \%$ for the Stanmore hinged prosthesis. Knutson et al (1986) reported a six year survival of $75 \%$ with the Guepar prosthesis.

Our overall success was comparable between knees with diagnoses of osteoarthritis and rheumatoid arthritis, and this has been shown in other studies (Lewallen et al 1984 ; Knutson et al 1986).

Survivorship analysis of total hip replacement using 
the same end-point of failure allows comparison with our series of total knee replacement. Dobbs (1980) in reviewing 173 metal on metal Stanmore total hip replacements reported an 11 -year overall survival of $53 \%$ and with 248 metal on plastic Stanmore total hip replacements an eight-year overall survival of $88 \%$. Ritter and Campbell (1987) reported a 15-year overall survival of $65.4 \%$ with the Charnley total hip prosthesis, a 14-year overall survival of $55.8 \%$ with the Muller hip prosthesis and an 11-year overall survival of $82.8 \%$ with the Trapezoidal- 28 hip prosthesis. The overall survival with total knees in our study appears better. Women and older patients had a significantly higher success rate as reported by Ritter and Campbell (1987), but this was not found in our total knee series.

In conclusion, cemented total knee replacement has been a reliable procedure which so far has withstood the test of time. The overall success does not appear to be influenced by diagnosis, sex, age or percentage of ideal body weight. At present, the posterior stabilised prosthesis with a metal-backed tibial component is our prosthesis of choice for primary total knee replacement.

Good surgical technique, in particular component positioning, knee alignment, soft-tissue balance and minimal tibial resection, remains essential in obtaining a long lasting arthroplasty.

One or more of the authors have received or will receive benefits for personal or professional use from a commercial party related directly or indirectly to the subject of this article. In addition benefits have also been or will be directed to a research fund, foundation, educational institution, or other non-profit institution with which one or more of the authors is associated.

\section{REFERENCES}

Armitage P. Statistical methods in medical research. Oxford and Edinburgh: Blackwell Scientific, 1971.

Bartel DL, Burstein AH, Santavicca EA, Insall JN. Performance of the tibial component in total knee replacement: conventional and revision designs. J Bone Joint Surg [Am] 1982; 64-A :1026-33.

Dobbs HS. Survivorship of total hip replacements. J Bone Joint Surg [Br] 1980; 62-B:168-73.

Grimer RJ, Karpinski MRK, Edwards AN. The long-term results of Stanmore total knee replacements. J Bone Joint Surg [Br] 1984; 66-B:55-62.

Insall JN, Hood RW, Flawn LB, Sullivan DJ. The total condylar knee prosthesis in gonarthrosis: a five to nine-year follow-up of the first one hundred consecutive replacements. J Bone Joint Surg [Am] 1983; 65-A :619-28.

Insall JN, Kelly M. The total condylar prosthesis. Clin Orthop 1986; 205:43-8.

Insall JN, Lachiewicz PF, Burstein AH. The posterior stabilized condylar prosthesis: a modification of the total condylar design: two to four-year clinical experience. J Bone Joint Surg [Am] 1982; 64-A :1317-23.

Insall J, Scott WN, Ranawat CS. The total condylar knee prosthesis: a report of two hundred and twenty cases. J Bone Joint Surg [Am] $1979 ; 61-A: 173-80$.
Knutson K, Lindstrand A, Lidgren L. Survival of knee arthroplasties: a nation-wide multicentre investigation of 8000 cases. $J$ Bone Joint Surg [ $\mathrm{Br}]$ 1986; 68-B:795-803.

Knutson K, Tjörnstrand B, Lidgren L. Survival of knee arthroplasties for rheumatoid arthritis. Acta Orthop Scand 1985; $56: 422-5$.

Lettin AWF, Kavanagh TG, Craig D, Scales JT. Assessment of the survival and the clinical results of Stanmore total knee replacements. J Bone Joint Surg [ Br] 1984; 66-B:355-61.

Lewallen DG, Bryan RS, Peterson LFA. Polycentric total knee arthroplasty: a ten-year follow-up study. J Bone Joint Surg [Am] $1984 ; 66-A: 1211-8$

Ritter MA, Campbell ED. Long-term comparison of the Charnley, Muller and Trapezoidal-28 total hip prostheses : a survival analysis. J Arthroplasty 1987; $1: 299-308$.

Tew M, Waugh W, Forster IW. Comparing the results of different types of knee replacements: a method proposed and applied. $J$ Bone Joint Surg [ Br] 1985; 67-B:775-9.

Tew $M$, Waugh W. Estimating the survival time of knee replacements. $J$ Bone Joint Surg [ Br] 1982; 64-B:579-82.

Vince KG, Kelly MA, Insall JN. Posterior stabilized knee prosthesis: follow up at five to eight years. Orthopaedic Transactions 1988: 12:157. 